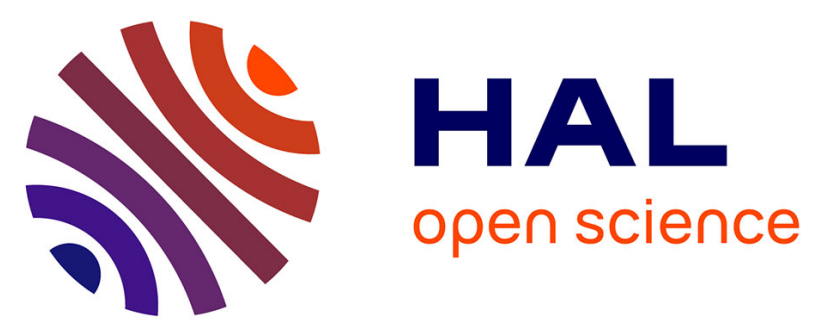

\title{
Peculiarities of crystal structures and photophysical properties of Ga III /Ln III metallacrowns with a non-planar [12-MC-4] core
}

Tu Nguyen, Svetlana Eliseeva, Chun Chow, Jeff Kampf, Stephane Petoud, Vincent Pecoraro

\section{To cite this version:}

Tu Nguyen, Svetlana Eliseeva, Chun Chow, Jeff Kampf, Stephane Petoud, et al.. Peculiarities of crystal structures and photophysical properties of Ga III /Ln III metallacrowns with a non-planar [12-MC-4] core. Inorganic Chemistry Frontiers, 2020, 7 (7), pp.1553-1563. 10.1039/c9qi01647c . hal-02935785

\section{HAL Id: hal-02935785 \\ https://hal.science/hal-02935785}

Submitted on 16 Nov 2020

HAL is a multi-disciplinary open access archive for the deposit and dissemination of scientific research documents, whether they are published or not. The documents may come from teaching and research institutions in France or abroad, or from public or private research centers.
L'archive ouverte pluridisciplinaire HAL, est destinée au dépôt et à la diffusion de documents scientifiques de niveau recherche, publiés ou non, émanant des établissements d'enseignement et de recherche français ou étrangers, des laboratoires publics ou privés. 


\title{
Peculiarities of crystal structures and photophysical properties of Ga"'/Ln"' metallacrowns with a non-planar [12-MC-4] core
}

Received 00th January 20xx, Accepted 00th January 20xx DOI: $10.1039 / \times 0 \times x 00000 x$

Tu N. Nguyen, ${ }^{\ddagger, a, c}$ Svetlana V. Eliseeva, ${ }^{*, \neq, b}$ Chun Y. Chow, ${ }^{a}$ Jeff W. Kampf, ${ }^{\text {a }}$ Stéphane Petoud, ${ }^{*, b}$ and Vincent L. Pecoraro*,a

\begin{abstract}
A new series of gallium(III)/lanthanide(III) metallacrown (MC) complexes (Ln-1) was synthesized by the direct reaction of salicylhydroxamic acid $\left(\mathrm{H}_{3}\right.$ shi) with Ga'l' and $\mathrm{Ln}^{\text {"II }}$ nitrates in a $\mathrm{CH}_{3} \mathrm{OH}$ /pyridine mixture. X-ray single crystal analysis revealed two types of structures depending on whether the nitrate counterion coordinate or not to the $\mathrm{Ln}^{\prime \prime \prime}$ :

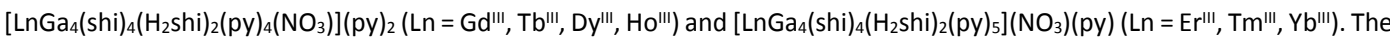
representative Tb-1 and Yb-1 MCs consist of a Tb/YbGa4 core with four [Ga"'- $-\mathrm{N}-\mathrm{O}$ ] repeating units forming a non-planar ring that coordinates the central $\mathrm{Ln}^{\text {"I' }}$ through the oxygen atoms of the four shi ${ }^{3-}$ groups. $\mathrm{Two}_{2} \mathrm{H}_{2} \mathrm{Sh}^{-}$groups bridge the $\mathrm{Ln}^{\text {III }}$ to the Ga"' ring ions. The $\mathrm{Yb}^{\text {"I' }}$ in $\mathbf{Y b}-\mathbf{1}$ is eight-coordinated while the ligation of the nine-coordinated Tb"l' in Tb-1 is completed by one chelating nitrate ion. Ln-1 complexes in the solid state showed characteristic sharp f-f transitions in the visible (Tb, Dy) and near-infrared (Dy, Ho, Er, $\mathrm{Yb}$ ) spectral ranges upon excitation into the ligand-centered electronic levels at $350 \mathrm{~nm}$. Observed luminescence lifetimes and absolute quantum yields were collected and discussed. For Yb-1, luminescence data were also acquired in $\mathrm{CH}_{3} \mathrm{OH}$ and $\mathrm{CD}_{3} \mathrm{OH}$ solutions and a more extensive analysis of photophysical properties was performed. This work demonstrates that while obtaining highly luminescent lanthanide(III) MCs via a direct synthesis is feasible, many factors such as molar absorptivities, triplet state energies, non-radiative deactivations through vibronic coupling with overtones of $\mathrm{O}-\mathrm{H}, \mathrm{N}-\mathrm{H}$, and $\mathrm{C}-\mathrm{H}$ oscillators and crystal packing will strongly contribute to the luminescent properties and should be carefully considered.
\end{abstract}

\section{Introduction}

Photoluminescence is a light-emitting process based on the absorption of photons, which brings a compound to an excited state that emits light when returning to the ground state. Photoluminescence can be obtained from a variety of compounds, for example, proteins, ${ }^{1}$ organic molecules and polymers, ${ }^{2}, 3$ semiconductor nanocrystals (quantum dots), ${ }^{4}$ inorganic pigments, ${ }^{5}$ transition metal complexes, ${ }^{6}$ and lanthanide(III) (Ln'I) complexes and nanomaterials. ${ }^{7,} 8$ The unique properties of $\mathrm{Ln}^{\text {III }}$ compounds that complement those of other luminophores include their characteristic sharp emission bands the wavelengths of which depends on the nature of the Ln'I and are non-sensitive to changes in their environments, long luminescence lifetimes, and strong resistance to photobleaching, which make them highly appealing for a broad

\footnotetext{
a. Department of Chemistry, Willard H. Dow Laboratories, University of Michigan, Ann Arbor, Michigan 48109, USA.*Email: V. L. Pecoraro, vlpec@umich.edu

b. Centre de Biophysique Moléculaire, CNRS UPR 4301, F-45071 Orléans Cedex 2, France. *Emails: S.V. Eliseeva, svetlana.eliseeva@cnrs-orleans.fr; S. Petoud, stephane.petoud@inserm.fr

Current address: Helen Scientific Research and Technological Development Co., Ltd, Ho Chi Minh City, Vietnam.

tElectronic Supplementary Information (ESI) available: supplementary tables, figures, and X-ray crystallographic parameters, including CIF files (CCDC 1965633 1965634). See DOI: 10.1039/x0xx00000x

${ }^{\ddagger}$ These authors contributed equally
}

variety of applications in materials sciences as well as for bioanalysis and biological imaging. ${ }^{9-20}$

Most of Ln'II ions are luminescent and exhibit characteristic emission in the visible and/or near-infrared (NIR) ranges due to their electronic transitions within $4 \mathrm{f}$ orbitals. However, because of the forbidden nature of most of $f-f$ transitions, $\mathrm{Ln}^{\text {III }}$ ions are very weak light absorbers, with molar absorptivities $(\varepsilon)$ in solution often smaller than $10 \mathrm{M}^{-1} \mathrm{~cm}^{-1}$. $^{21}$ Thus, the direct excitation of $\mathrm{Ln}^{\mathrm{III}}$ ions is rather inefficient. To overcome this limitation, chromophoric organic sensitizing ligands named "antenna" that possess large $\varepsilon$ are often employed to synthesize luminescent L ${ }^{\prime \prime \prime}$ complexes. ${ }^{22}$ With this strategy, the excitation light can be efficiently absorbed in the system and the resulting energy can be transferred to the accepting levels of Ln'II. The subsequent $f-f$ emission occurs when the system relaxes back to the ground state. The nature of the chromophoric ligands, their molar absorption coefficients, their abilities to protect Ln $^{\text {III }}$ ions from non-radiative deactivations and to efficiently sensitize them are main parameters to consider when designing Ln $^{\text {III-containing luminescent }}$ compounds. ${ }^{23}$

Our group has recently initiated an innovative approach to create highly luminescent $\mathrm{Ln}^{\prime \prime \prime}$-based probes and materials by utilizing metallacrown complexes. ${ }^{24-30}$ Metallacrowns (MCs) are a unique class of inorganic macrocycles that consist of repeating [Metal-N-O] subunits. ${ }^{31}$ With structural similarity to crown ethers, MCs are capable of binding a central metal ion through 
the hydroximate oxygen atoms. MCs have been extensively explored in the fields of selective ion recognition, ${ }^{32-38}$ molecular magnetism ${ }^{39-47}$ and magnetorefrigeration, ${ }^{48}$ as well as contrast agents for magnetic resonance imaging (MRI). ${ }^{49-51} \mathrm{In}$ view of the

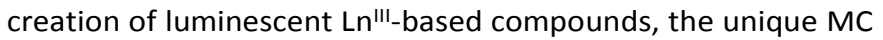
scaffolds combine a large number of chromophores able to efficiently absorb and sensitize characteristic Ln"I emission in

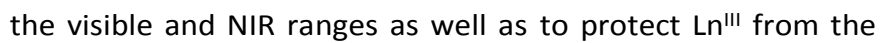
sources of non-radiative deactivations. Several families of highly luminescent MCs exhibiting characteristic Ln"l' emission have been described, e.g. $\mathrm{Ln}^{\prime \prime \prime} / \mathrm{Zn}^{\prime \prime}$ MCs with an "encapsulated sandwich" structure ${ }^{25,52}$ and Ln"'/Ga"I MCs with monomeric ${ }^{26}$ or dimeric ${ }^{28}$ structures assembled using salicylhydroxamic $\left(\mathrm{H}_{3} \mathrm{Shi}^{3-}\right.$ ) and benzoic ( $\mathrm{HOBz})$, or isophthalic $\left(\mathrm{H}_{2} \mathrm{i} \mathrm{ph}\right)$ acids, respectively. In this work, we present the syntheses, peculiarities of crystal structures and photophysical properties of a new series of Ga'I'/Ln"I MCs assembled using a direct reaction of the $\mathrm{H}_{3}$ shi ligand with Ga'll and Ln"' nitrates.

\section{Experimental}

All reagents and chemicals were purchased from commercial sources and used without further purification. All reactions were carried under aerobic conditions.

\section{Preparation of Complexes Ln-1}

$\mathrm{H}_{3}$ shi (153.1 mg, $\left.1.0 \mathrm{mmol}\right), \operatorname{Ln}\left(\mathrm{NO}_{3}\right)_{3} \cdot \mathrm{xH}_{2} \mathrm{O}(0.25 \mathrm{mmol})(\mathrm{Ln}$ Gd'"', Tb'"I, Dy"', $\mathrm{Ho}^{\prime \prime \prime}, \mathrm{Er}^{\prime \prime \prime}, \mathrm{Tm}^{\prime \prime \prime}$, and $\left.\mathrm{Yb}^{\prime \prime \prime}\right)$, and $\mathrm{Ga}\left(\mathrm{NO}_{3}\right)_{3} \cdot \mathrm{xH}_{2} \mathrm{O}$ (255.7 mg, $1.0 \mathrm{mmol}$ ) were dissolved in $10 \mathrm{~mL}$ methanol. Pyridine $(2 \mathrm{~mL})$ and acetic acid $(0.1 \mathrm{~mL})$ were added and the mixture was stirred for 20 mins. The solution was filtered and kept undisturbed. X-ray quality crystals form after one day. $\left[\mathrm{GdGa}_{4}(\mathrm{shi})_{4}\left(\mathrm{H}_{2} \mathrm{Shi}\right)_{2}(\mathrm{py})_{4}\left(\mathrm{NO}_{3}\right)\right] \cdot(\mathrm{py})_{2}(\mathrm{Gd}-1)$. Yield: $131 \mathrm{mg}$ (28\%). ESI-MS, calc. for [M] ${ }^{-}, \mathrm{C}_{42} \mathrm{H}_{26} \mathrm{~N}_{6} \mathrm{O}_{18} \mathrm{GdGa}_{4}, 1338.8$; found, 1337.9. Anal. Calcd for $\mathrm{GdGa}_{4} \mathrm{C}_{72} \mathrm{H}_{58} \mathrm{~N}_{13} \mathrm{O}_{21}$ : C, 46.06; $\mathrm{H}, 3.11 ; \mathrm{N}$, 9.70. Found: C, 46.02; $\mathrm{H}, 3.07 ; \mathrm{N}, 9.33$.

$\left[\mathrm{TbGa}_{4}(\mathrm{shi})_{4}\left(\mathrm{H}_{2} \mathrm{Shi}\right)_{2}(\mathrm{py})_{4}\left(\mathrm{NO}_{3}\right)\right] \cdot(\mathrm{py})_{2}(\mathrm{~Tb}-\mathbf{1})$. Yield: $153 \mathrm{mg}$ (33\%). ESI-MS, calc. for [M]', $\mathrm{C}_{42} \mathrm{H}_{26} \mathrm{~N}_{6} \mathrm{O}_{18} \mathrm{TbGa}_{4}, 1340.5$; found, 1339.8. Anal. Calcd for $\mathrm{TbGa}_{4} \mathrm{C}_{72} \mathrm{H}_{58} \mathrm{~N}_{13} \mathrm{O}_{21}: \mathrm{C}, 46.02 ; \mathrm{H}, 3.11 ; \mathrm{N}$, 9.69. Found: $\mathrm{C}, 46.31 ; \mathrm{H}, 3.20 ; \mathrm{N}, 9.64$.

$\left[\right.$ DyGa $\left.{ }_{4}(\mathrm{shi})_{4}\left(\mathrm{H}_{2} \mathrm{Shi}\right)_{2}(\mathrm{py})_{4}\left(\mathrm{NO}_{3}\right)\right] \cdot(\mathrm{py})_{2}$ (Dy-1). Yield: $151 \mathrm{mg}$ (32\%). ESI-MS, calc. for [M]-, $\mathrm{C}_{42} \mathrm{H}_{26} \mathrm{~N}_{6} \mathrm{O}_{18} \mathrm{DyGa}_{4}, 1344.1$; found, 1343.9. Anal. Calcd for DyGa ${ }_{4} \mathrm{C}_{72} \mathrm{H}_{58} \mathrm{~N}_{13} \mathrm{O}_{21}$ : C, 45.93; $\mathrm{H}, 3.11 ; \mathrm{N}$, 9.67. Found: $\mathrm{C}, 46.22 ; \mathrm{H}, 3.17 ; \mathrm{N}, 9.49$.

$\left[\mathrm{HoGa}_{4}(\mathrm{shi})_{4}\left(\mathrm{H}_{2} \mathrm{Shi}\right)_{2}(\mathrm{py})_{4}\left(\mathrm{NO}_{3}\right)\right] \cdot(\mathrm{py})_{2}$ (Ho-1). Yield: $147 \mathrm{mg}$ (31\%). ESI-MS, calc. for [M]', $\mathrm{C}_{42} \mathrm{H}_{26} \mathrm{~N}_{6} \mathrm{O}_{18} \mathrm{HoGa}_{4}, 1346.5$; found, 1346.8. Anal. Calcd for $\mathrm{HoGa}_{4} \mathrm{C}_{72} \mathrm{H}_{58} \mathrm{~N}_{13} \mathrm{O}_{21}$ : C, 45.87; $\mathrm{H}, 3.10 ; \mathrm{N}$, 9.66. Found: $\mathrm{C}, 46.10 ; \mathrm{H}, 3.13 ; \mathrm{N}, 9.48$.

$\left[\mathrm{ErGa}_{4}(\mathrm{shi})_{4}\left(\mathrm{H}_{2} \mathrm{Shi}\right)_{2}(\mathrm{py})_{5}\right]\left(\mathrm{NO}_{3}\right) \cdot(\mathrm{py})(\mathrm{Er}-1)$. Yield: $127 \mathrm{mg}(27 \%)$. ESI-MS, calc. for [M]', $\mathrm{C}_{42} \mathrm{H}_{26} \mathrm{~N}_{6} \mathrm{O}_{18} \mathrm{ErGa}_{4}, 1348.9$; found, 1347.9. Anal. Calcd for $\mathrm{ErGa}_{4} \mathrm{C}_{72} \mathrm{H}_{58} \mathrm{~N}_{13} \mathrm{O}_{21}$ : C, 45.82; $\mathrm{H}, 3.10 ; \mathrm{N}, 9.65$. Found: C, 45.68; $\mathrm{H}, 3.37$; N, 9.35.

$\left[\mathrm{TmGa}_{4}(\mathrm{shi})_{4}\left(\mathrm{H}_{2} \mathrm{shi}\right)_{2}(\mathrm{py})_{5}\right]\left(\mathrm{NO}_{3}\right) \cdot(\mathrm{py})(\mathrm{Tm}-1)$. Yield: $166 \mathrm{mg}$ (35\%). ESI-MS, calc. for [M]', $\mathrm{C}_{42} \mathrm{H}_{26} \mathrm{~N}_{6} \mathrm{O}_{18} \mathrm{TmGa}_{4}, 1350.5$; found,
1350.8. Anal. Calcd for $\mathrm{TmGa}_{4} \mathrm{C}_{72} \mathrm{H}_{58} \mathrm{~N}_{13} \mathrm{O}_{21}$ : C, 45.78; $\mathrm{H}, 3.09 ; \mathrm{N}$, 9.64. Found: $\mathrm{C}, 45.48 ; \mathrm{H}, 3.35 ; \mathrm{N}, 9.26$.

$\left[\mathrm{YbGa}_{4}(\mathrm{shi})_{4}\left(\mathrm{H}_{2} \mathrm{shi}\right)_{2}(\mathrm{py})_{5}\right]\left(\mathrm{NO}_{3}\right) \cdot(\mathrm{py}) \quad(\mathrm{Yb}-1)$. Yield: $114 \mathrm{mg}$ (24\%). ESI-MS, calc. for [M]', $\mathrm{C}_{42} \mathrm{H}_{26} \mathrm{~N}_{6} \mathrm{O}_{18} \mathrm{YbGa}_{4}, 1354.6$; found, 1353.8. Anal. Calcd for $\mathrm{YbGa}_{4} \mathrm{C}_{72} \mathrm{H}_{58} \mathrm{~N}_{13} \mathrm{O}_{21}: \mathrm{C}, 45.68 ; \mathrm{H}, 3.09 ; \mathrm{N}$, 9.62. Found: $\mathrm{C}, 45.85 ; \mathrm{H}, 3.30 ; \mathrm{N}, 9.31$.

\section{X-Ray Crystallography}

Single-crystal X-ray crystallographic data for the Tb-1 and Yb-1 MCs were collected at 85(2) K on an Rigaku AFC10K Saturn 944+ CCD-based X-ray diffractometer equipped with a Micromax007HF Cu-target microfocus rotating anode $(\lambda=$ $1.54187 \AA$ ) $)$, operated at $1200 \mathrm{~W}$ power ( $40 \mathrm{kV}, 30 \mathrm{~mA})$. The data were processed with the program CrystalClear 2.0 and corrected for absorption. The structure was solved and refined with the program SHELXTL (version 6.12). ${ }^{53}$ All non-hydrogen atoms were refined anisotropically. Hydrogen atoms were placed in their idealized positions. The structure of Tb-1 contains large solvent accessible voids totalling $939 \AA^{3}$ and 107 electrons per unit cell. This region has diffuse electron density and could not be modelled with any chemically reasonable moieties. Thus, the SQUEEZE routine of the PLATON suite of programs ${ }^{54}$ was applied to remove the diffraction contribution from these solvent molecules. Experimental parameters and crystallographic data for Tb-1 and $\mathbf{Y b - 1}$ are provided in Table S1. For other Ln-1 compounds, unit cell parameters were collected and showed in Table S2.

\section{Photophysical Measurements}

Luminescence data were collected on samples placed into 2.4 $\mathrm{mm}$ i.d. quartz capillaries or quartz Suprasil cells. Emission and excitation spectra were measured on a Horiba-Jobin-Yvon Fluorolog 3 spectrofluorimeter equipped with either a visible photomultiplier tube (PMT) (220-800 nm, R928P; Hamamatsu), a NIR solid-state InGaAs detector cooled to $77 \mathrm{~K}$ (800-1600 nm, DSS-IGA020L; ElectroOptical Systems, Inc., USA ), or a NIR PMT (950-1650 nm, H10330-75; Hamamatsu). All spectra were corrected for instrumental functions. Luminescence lifetimes were determined under excitation at $355 \mathrm{~nm}$ provided by a Nd:YAG laser (YG 980; Quantel), the signals in the visible and the NIR ranges were detected by the R928 or H10330-75 PMTs. The output signals from the detectors were then fed into a $500 \mathrm{MHz}$ bandpass digital oscilloscope (TDS 754C; Tektronix), transferred to a PC and data were processed with the program Origin $8^{\circ}$. Luminescence lifetimes are averages of three or more independent measurements. Quantum yields were determined with a Fluorolog 3 spectrofluorimeter based on the absolute method using an integration sphere (GMP SA). Each sample was measured several times varying the position of samples. Estimated experimental error for the determination of quantum yields is estimated as $\sim 10 \%$. 


\section{ARTICLE}
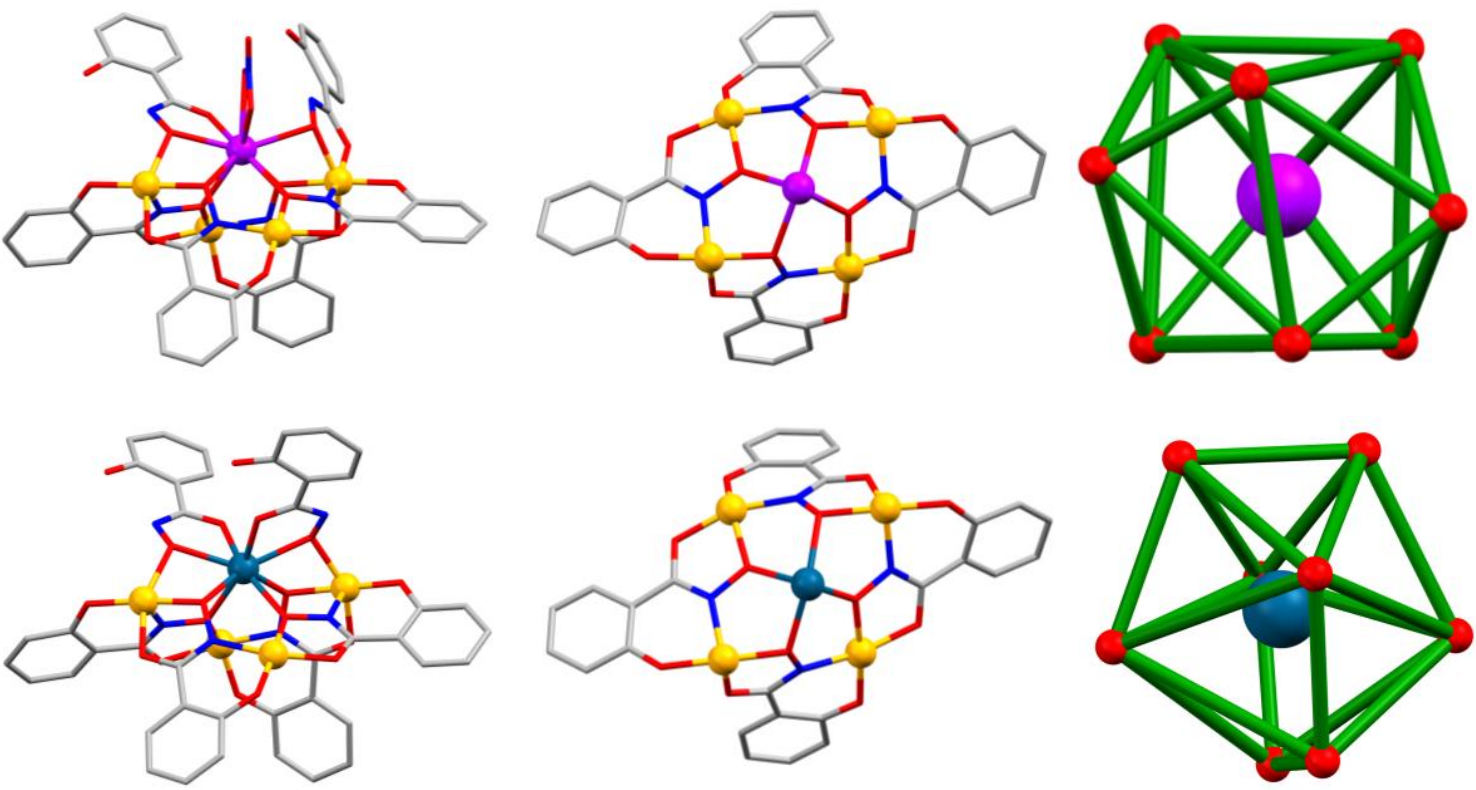

Figure 1 (Top) X-ray crystal structure of Tb-1 in side-view (left), top-down view of the bent [12-MC-4] core (middle), and coordination geometry around the central Tb"l' ion (right), (Bottom) X-ray crystal structure of Yb-1 in side-view (left), top-down view of the bent [12-MC-4] core (middle), and coordination geometry around the central Yb"II ion (right). Hydrogen atoms and solvent molecules have been omitted for clarity. Color code: Tb purple; Yb cyan; Ga yellow; $\mathrm{O}$ red; $\mathrm{N}$ blue; $\mathrm{C}$ grey.

\section{Absorption Spectroscopy}

Solid-state UV-Vis spectra were collected with the help of an Agilent-Cary 5000 spectrophotometer equipped with a Praying Mantis diffuse reflectance accessory. Spectra were collected in reflectance $(R)$ mode. The signal of $\mathrm{BaSO}_{4}$ was used as the reference to establish the baseline. Samples (10 wt. \%) were mulled in $\mathrm{BaSO}_{4}$ (90 wt. \%). The spectra were then converted into Kubelka-Munk function to represent more accurately the absorption and plotted vs. wavelength. UV-Vis absorption spectra of the compounds dissolved in $\mathrm{CH}_{3} \mathrm{OH}$ were recorded on a Cary 100Bio UV-Vis spectrophotometer in absorbance mode.

\section{ESI-Mass Spectrometry}

ESI-MS spectra were collected with a Micromass LCT time-offlight electrospray mass spectrometer in a negative ion mode at cone voltages ranging from -40 to $-70 \mathrm{~V}$ on samples dissolved in $\mathrm{CH}_{3} \mathrm{OH}$. Samples were injected via syringe pump. Data were processed with the program MassLynx 4.0.

\section{Results}

\section{Syntheses}

The reaction between $\mathrm{H}_{3}$ shi and nitrates of Ga'I' and $\mathrm{Ln}^{\text {"II }}$ (Gd"I', $\mathrm{Tb}^{\prime \prime \prime}, \mathrm{Dy} \mathrm{Dy}^{\mathrm{II}}, \mathrm{Ho}^{\prime \prime \prime}, \mathrm{Er}^{\mathrm{III}}, \mathrm{Tm}^{\prime \prime \prime}$, and $\mathrm{Yb}^{\prime \prime \prime}$ ) in a $\mathrm{CH}_{3} \mathrm{OH}$ /pyridine mixture in presence of a small amount of acetic acid affords Ln-1 complexes. The general reaction is shown in Scheme 1. The synthetic conditions were similar for all the $\mathrm{Ln}^{\text {III }}$ salts used in the reactions. The complexes with early $\mathrm{Ln}^{\prime \prime \prime}$ ions such as $\mathrm{Nd}^{\prime \prime \prime}, \mathrm{Sm}^{\prime \prime \prime}$, and Eu'I' were formed together with a mixture of unidentified complexes and could not be isolated individually.

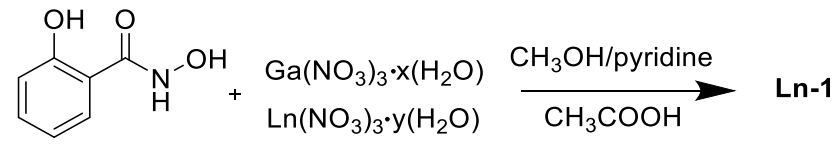

Scheme 1 Synthesis of Ln-1 complexes.

\section{X-ray crystal structures}

Ln-1 complexes crystallize in two different systems as presented in Table S2. The X-ray crystal structures of the two representative molecules, Tb-1 and Yb-1, are shown in Figure 1. Both Tb-1 and Yb-1 crystallized in the triclinic $P \overline{1}$ space group. The molecule Tb-1 contains a $\mathrm{TbGa}_{4}$ core with four [Ga'II-N-O] repeating units forming a non-planar [12-MC-4] ring that coordinates the central Tb"l' ion through the oxygen atoms of the hydroximate groups. The Tb"l' ion is further bridged to two Gall' ions located in the ring by two mono-deprotonated $\mathrm{H}_{2} \mathrm{Shi}^{-}$ 
groups and its coordination sphere is filled by a chelating nitrate. The 9-coordinate $\mathrm{Tb}^{\prime \prime \prime}$ ion adopts a coordination geometry close to a tricapped trigonal prism as determined by the program SHAPE (Table S3). ${ }^{55} \mathbf{~ Y b - 1}$ has a similar non-planar [12-MC-4] core as Tb-1. The two mono-deprotonated $\mathrm{H}_{2} \mathrm{Shi}^{-}$ groups bridge the central $\mathrm{Yb}^{\prime \prime \prime}$ and two Gall' ions located in the ring and result in an eight-coordinated $\mathrm{Yb}^{\prime \prime \prime}$ ion that adopts a coordination geometry close to triangular dodecahedron (Table S4). The charge of the Yb-1 complex is balanced by one nitrate counter anion.

\section{Photophysical properties}

Ligand-centered photophysical properties. The UV-Vis absorption spectra of $\mathrm{H}_{3}$ shi and $\mathbf{L n - 1}$ complexes were collected in $\mathrm{CH}_{3} \mathrm{OH}$ solutions. Reflectance spectra of $\mathbf{~} \mathbf{n}-\mathbf{1}$ complexes were collected in the solid state. $\mathrm{H}_{3}$ shi exhibits broad absorption bands in solution resulting from $\pi \rightarrow \pi^{*}$ transitions in the UV region extending up to $340 \mathrm{~nm}$ with an apparent maximum of the band centered at $2300 \mathrm{~nm}\left(\varepsilon=3.9 \cdot 10^{3} \mathrm{M}^{-1} \mathrm{~cm}^{-1}\right.$, Figure 2). Ln-1 complexes display a slight red shift of their corresponding absorption bands in solution, as shown in Figure 2 for the Gd-1 complex (Figure S1, top for all Ln-1 complexes) associated with large molar absorptivities $\left(\varepsilon_{\mathrm{Gd}-1}=3.29 \cdot 10^{4} \mathrm{M}^{-1} \mathrm{~cm}^{-1}\right.$ at $\left.307 \mathrm{~nm}\right)$ due to the combined contribution of the six ligands derived from $\mathrm{H}_{3}$ shi. Diffuse reflectance spectra of the $\mathbf{L n} \mathbf{- 1}$ complexes (Figure S1, bottom) are dominated by broad bands that correspond to the contribution of the ligands. Sharper bands with significantly lower intensities are observed above wavelength values of 400 $\mathrm{nm}$. These narrow bands can unambiguously be assigned to $f-f$ transitions of the corresponding $\mathrm{Ln}^{\prime \prime \prime}$ ions, and are particularly pronounced for Ho'll and Er'll ions (Figure S1, bottom). UV-Vis absorption and reflectance spectra of the $\mathbf{L n - 1}$ complexes are nearly superimposable indicating that the nature of the $\mathrm{Ln}^{\mathrm{II}}$ ions does not significantly affect the electronic structures of the chromophoric ligands and the corresponding positions of the ligand-centered bands.

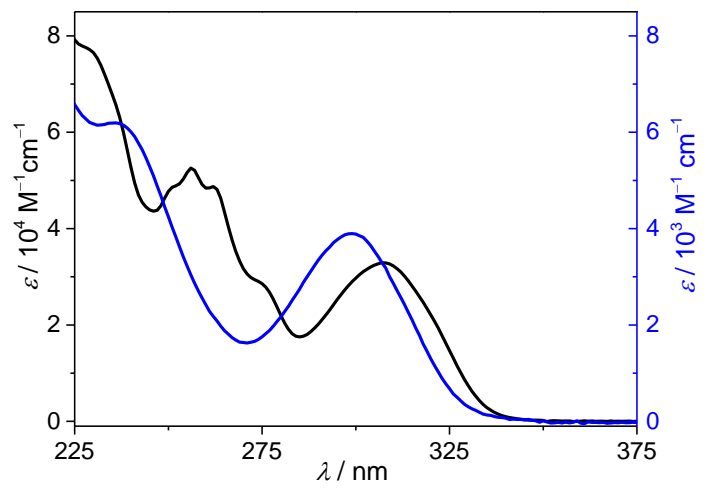

Figure 2 Absorption spectra of the Gd-1 MC recorded in $\mathrm{CH}_{3} \mathrm{OH}$ solutions (black trace, left scale) and $\mathrm{H}_{3}$ shi (blue trace, right scale).

An important factor that is assumed to play a significant role in the sensitization of luminescent $\mathrm{Ln}^{\text {III }}$ ions in their complexes is the energy position of the triplet state $\left({ }^{3} \mathrm{~T}\right)$ of the organic ligands. The energy of the ${ }^{3} \mathrm{~T}$ level in $\mathbf{~} \mathbf{n}-\mathbf{1}$ can be estimated from the phosphorescence spectrum of the corresponding Gd"II complex. Phosphorescence intensity is promoted due to heavyatom and paramagnetic effects induced by the $\mathrm{Gd}^{\text {III }}$ ion. ${ }^{56}$ In addition, the accepting electronic level of $\mathrm{Gd}^{\prime \prime \prime \prime}$ is located at sufficiently high energy $\left(\sim 32000 \mathrm{~cm}^{-1}\right)^{57}$ to prevent its population through electronic levels of most organic ligands. Gd-1 MC exhibits the phosphorescence signal shown in Figure 3. The spectrum was recorded in time-resolved mode in the solid state at $77 \mathrm{~K}$ upon excitation at $325 \mathrm{~nm}$ and using a $100 \mu \mathrm{s}$ delay after the excitation flash to remove any fluorescence signal arising from the singlet state. The Gaussian decomposition of the phosphorescence spectrum allowed to estimate the energy of the $0-0$ transition, that is located at $461.6 \mathrm{~nm}\left(\sim 21660 \mathrm{~cm}^{-1}\right)$ and represents the energy of the triplet state.

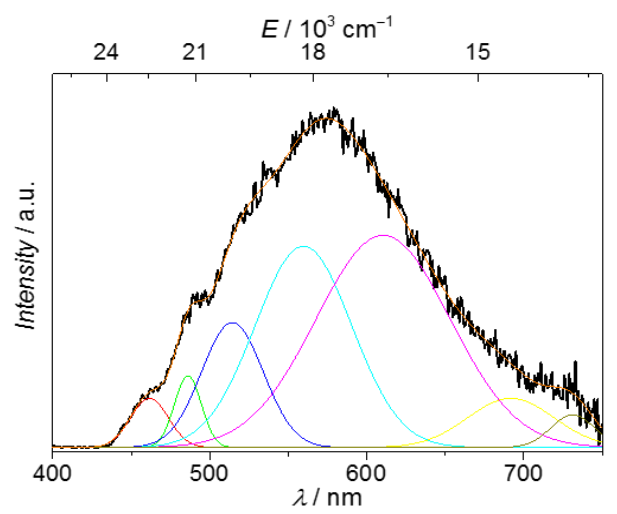

Figure 3 Phosphorescence spectrum of the Gd-1 MC measured in the solid state under excitation at $325 \mathrm{~nm}(77 \mathrm{~K}, 100 \mu$ s delay after the excitation flash, black trace) and its Gaussian decomposition (colored traces).

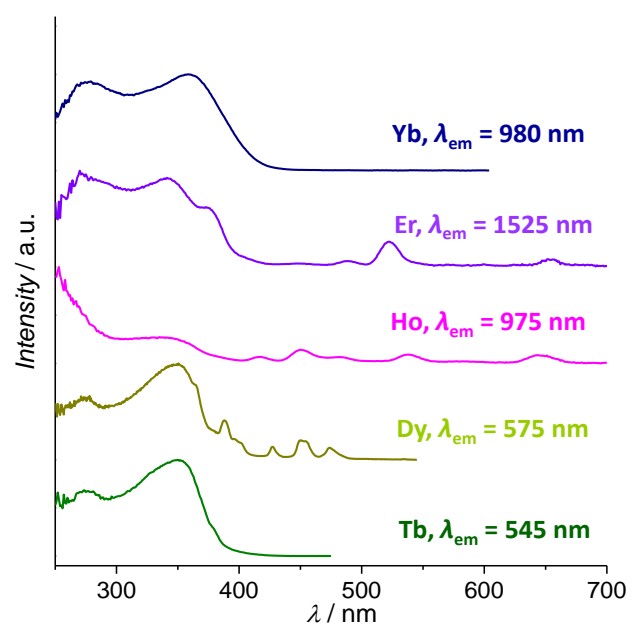

Figure 4 Corrected and normalized excitation spectra of the Ln-1 MCs in the solid state upon monitoring the main transitions of the corresponding $\mathrm{Ln}^{\text {III }}$ ions at room temperature.

Lanthanide-centered photophysical properties. Excitation and emission spectra of all Ln-1 complexes were collected in the solid state. Since Ln'II ions exhibit characteristic emission bands, excitation spectra can be obtained by monitoring the specific $f$ $\mathrm{f}$ transitions of the corresponding Ln'II ion. 
The excitation spectra of the $\mathbf{L n - 1}$ complexes recorded in the solid state (Figure 4) are similar to the corresponding absorption and reflectance spectra (Figure S1) and exhibit broad bands in the range $250-400 \mathrm{~nm}$. This observation indicate that the sensitization of the five $\mathrm{Ln}^{\text {III }}$ tested here is occurring in each case through the electronic state located on the organic chromophoric part of the MCs. A slight extension towards longer wavelengths is observed due to the saturation effects (Figure S2). ${ }^{58}$ In addition, sharper bands with lower intensity that can be attributed to $f-f$ transitions are detected

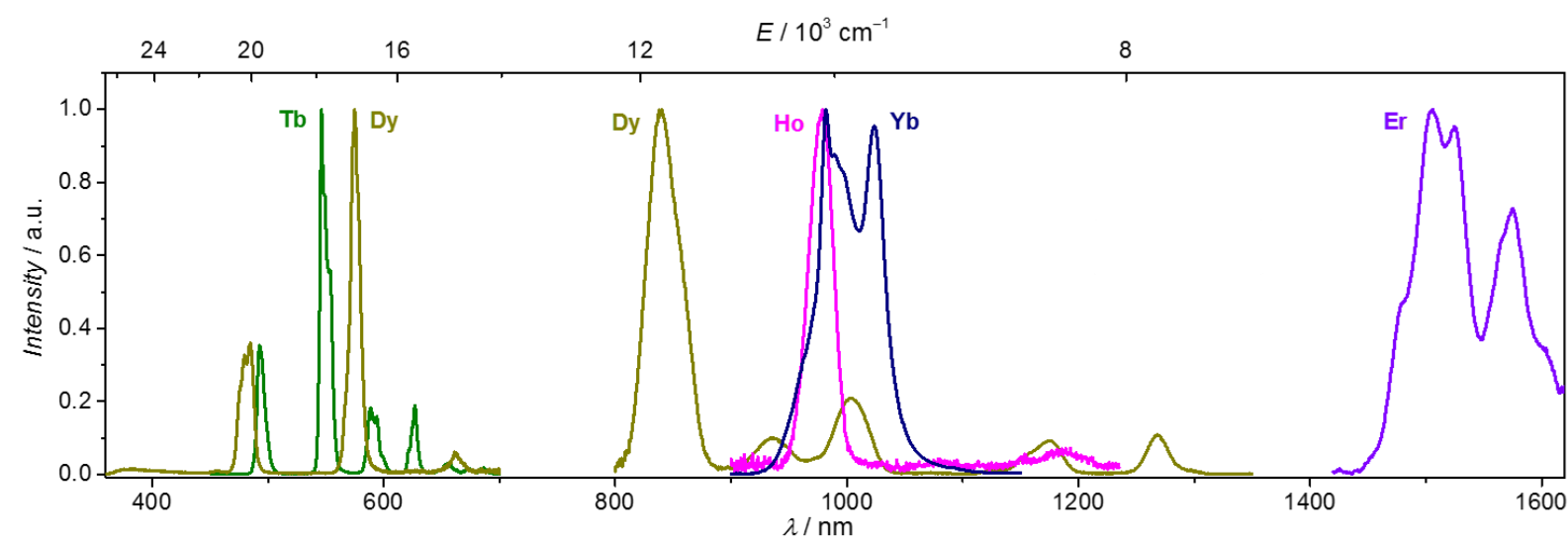

Figure 5 Corrected and normalized emission spectra of the $\mathbf{L n - 1}$ MCs in the solid state under excitation at $350 \mathrm{~nm}$ at room temperature.

for Er'II, Ho'II, and Dy"l' MCs. The study of the excitation spectra allows for the determination of the excitation wavelengths of Ln-1 complexes corresponding to the highest emission intensities, which are $\sim 350 \mathrm{~nm}$ for the solid samples. Thus, emission spectra were collected for $\mathbf{L n - 1}$ samples in the solid state upon excitation at $350 \mathrm{~nm}$ at room temperature (Figure 5). Characteristic emissions of $L n^{\prime \prime \prime}$ ions in the visible (Tb'II), NIR

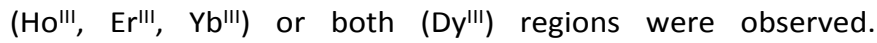
Luminescence lifetimes ( $\left.\tau_{\text {obs }}\right)$ and absolute Ln ${ }^{\text {III-centred }}$ quantum yields under ligands excitation $\left(Q_{\mathrm{Ln}}^{\mathrm{L}}\right)$ were also acquired as quantitative luminescence data; the results are summarized in Table 1.

Tb-1 exhibits green emission resulting from the ${ }^{5} D_{4} \rightarrow{ }^{7} F_{J}(J=6$ -0 ) transitions. The four prominent bands centered at $\sim 493$, 545,589 and $627 \mathrm{~nm}$ correspond to ${ }^{5} \mathrm{D}_{4} \rightarrow{ }^{7} \mathrm{~F}_{6,5,4,3}$ transitions whereas the other three transitions ${ }^{5} \mathrm{D}_{4} \rightarrow{ }^{7} \mathrm{~F}_{2,1,0}$ are of significantly lower intensity and observed in the range 640 - 700 $\mathrm{nm}$. The relative integral intensities of different transitions for Tb-1 are given in Table S2. The solid state sample has ta $Q_{\mathrm{Tb}}^{\mathrm{L}}$ value of $11.3 \%$ and a $\tau_{\text {obs }}$ of $509 \mu \mathrm{s}$.

Dy-1 exhibits a number of bands across the visible and the NIR regions arising from the ${ }^{4} \mathrm{~F}_{9 / 2} \rightarrow{ }^{6} \mathrm{H}_{J}(J=15 / 2-5 / 2)$ and ${ }^{4} \mathrm{~F}_{9 / 2} \rightarrow$ ${ }^{6} F_{J}(J=9 / 2-3 / 2)$ electronic transitions. In the visible region, the spectrum is dominated by two bands centered at 483 and 574 $\mathrm{nm}$ corresponding to the ${ }^{4} \mathrm{~F}_{9 / 2} \rightarrow{ }^{6} \mathrm{H}_{15 / 2,13 / 2}$ transitions. These bands are responsible for the apparent yellow-green emission of this MC. In the NIR region, beside the high-intensity band at $840 \mathrm{~nm}$ originating from the ${ }^{4} \mathrm{~F}_{9 / 2} \rightarrow{ }^{6} \mathrm{~F}_{9 / 2},{ }^{6} \mathrm{H}_{7 / 2}$ transitions, the emission bands at 937, 1005, 1177 and $1269 \mathrm{~nm}$ corresponding to ${ }^{4} \mathrm{~F}_{9 / 2} \rightarrow{ }^{6} \mathrm{H}_{5 / 2},{ }^{4} \mathrm{~F}_{9 / 2} \rightarrow{ }^{6} \mathrm{~F}_{7 / 2},{ }^{4} \mathrm{~F}_{9 / 2} \rightarrow{ }^{6} \mathrm{~F}_{5 / 2}$ and ${ }^{4} \mathrm{~F}_{9 / 2} \rightarrow{ }^{6} \mathrm{~F}_{3 / 2}$ transitions can be detected. The residual broad ligand-centered emission signal is observed in the $375-550 \mathrm{~nm}$ range and can be explained by an incomplete energy transfer to Dy $\mathrm{y}^{\text {III }}$ or an energy back transfer from Dy"l' to the ligands due to the close energy difference between the ${ }^{4} \mathrm{~F}_{9 / 2}$ and the ${ }^{3} \mathrm{~T}$ levels. Measured Dy'l'-centered quantum yield values of the solid state sample in the visible and the NIR regions are 0.22 and $0.013 \%$, respectively. The total quantum yield of Dy-1 in the visible range is $0.23 \%$, so that the ligand contribution to the total emission can be estimated to $3.9 \%$.

Ho-1 exhibits a NIR emission of relatively low intensity with maxima at 978 and $1188 \mathrm{~nm}$ due to the ${ }^{5} \mathrm{~F}_{5} \rightarrow{ }^{5} \mathrm{I}_{7}$ and ${ }^{5} \mathrm{I}_{6} \rightarrow{ }^{5} \mathrm{I}_{8}$ transitions, respectively. The $Q_{\mathrm{Ho}}^{\mathrm{L}}$ value of Ho-1 in the solid state is $1.6 \cdot 10^{-3} \%$ and the observed lifetime is equal to $32 \mathrm{~ns}$.

Er-1 exhibits a relatively broad NIR emission band in the range of $1500-1620 \mathrm{~nm}$ corresponding to the $\left.\left.{ }^{4}\right|_{13 / 2} \rightarrow{ }^{4}\right|_{15 / 2}$ transition. The Er'II-centered quantum yield is similar to the one of Ho-1, $1.55 \cdot 10^{-3} \%$. In contrast, the observed lifetime is significantly longer with a value of $220 \mathrm{~ns}$.

Tm-1 does not exhibit any emission due to $f-f$ transitions or the emission signal is too weak to be detected.

Yb-1 exhibits a NIR emission band in the range $900-1150 \mathrm{~nm}$ arising from the ${ }^{2} \mathrm{~F}_{5 / 2} \rightarrow{ }^{2} \mathrm{~F}_{7 / 2}$ transition. The $Q_{\mathrm{Yb}}^{\mathrm{L}}$ of the solid state sample is $0.216 \%$, and the observed luminescence lifetime $\tau_{\text {obs }}$ is $2.99 \mu \mathrm{s}$. Photophysical properties of this sample were also studied in $\mathrm{CH}_{3} \mathrm{OH}$ and $\mathrm{CD}_{3} \mathrm{OD}$ solutions (Figure 6). It was found that the crystal field splitting of the ${ }^{2} \mathrm{~F}_{5 / 2} \rightarrow{ }^{2} \mathrm{~F}_{7 / 2}$ transition is different for the sample in solution compared to the one in the solid state. Such behavior reflects changes in coordination environment around $\mathrm{Yb}^{\prime \prime \prime}$ between the two phases. Indeed, calculations of the hydration number taking into account the values of observed lifetimes collected in $\mathrm{CH}_{3} \mathrm{OH}$ and $\mathrm{CD}_{3} \mathrm{OD}$ and using the well-established phenomenological equation ${ }^{59}$ confirmed the coordination of one solvent molecule to $\mathrm{Yb}^{\prime \prime \prime}$. The quantum yield value in $\mathrm{CD}_{3} \mathrm{OD}$ is 12 -fold higher $(2.55$ 
\%) than the one obtained in the solid state, however it decreases to $0.12 \%$ in $\mathrm{CH}_{3} \mathrm{OH}$.

Radiative lifetime, intrinsic quantum yield $\left(Q_{\mathrm{Yb}}^{\mathrm{Yb}}\right)$ and sensitization efficiency ( $\eta_{\text {sens }}$ ) of $\mathbf{Y b}-\mathbf{1}$. Radiative lifetime $\left(\tau_{\mathrm{rad}}\right)$ is the lifetime of an electronic state when only radiative processes depopulate this level.

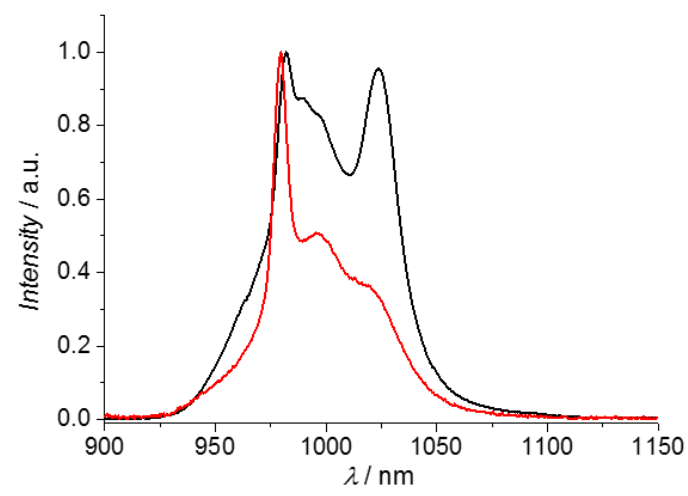

Figure 6 Corrected and normalized emission spectra of the Yb-1 MC collected in the solid state $\left(\lambda_{\text {ex }}=350 \mathrm{~nm}\right.$, black trace) and in methanol solutions $\left(\lambda_{\mathrm{ex}}=320 \mathrm{~nm}, 0.5 \mathrm{mM}\right.$, red trace) at room temperature.

In the case of $\mathbf{Y b - 1}, \tau_{\mathrm{rad}}$ can be calculated from the absorption spectrum in the range of ${ }^{2} \mathrm{~F}_{5 / 2} \leftarrow^{2} \mathrm{~F}_{7 / 2}$ transition (Figure 7) using the modified Einstein's equation: ${ }^{60}$

$\frac{1}{\tau_{\text {rad }}}=2303 \times \frac{8 \pi c n^{2} \widetilde{v}_{m}^{2}(2 J+1)}{N_{A}\left(2 J^{\prime}+1\right)} \int \varepsilon(\tilde{v}) d \tilde{v}$

$\tilde{v}_{m}=\frac{\int \widetilde{v} \varepsilon(\widetilde{v}) d \widetilde{v}}{\int \varepsilon(\widetilde{v}) d \widetilde{v}}$

where $c$ is the speed of light in centimeters per second, $\mathrm{n}$ is the refractive index, $N_{\mathrm{A}}$ is the Avogadro's number, $J$ and $J$ ' are the quantum numbers for the ground and excited states, respectively, $\int \varepsilon(\tilde{v}) d \tilde{v}$ is the integrated spectrum of the $\mathrm{f}-\mathrm{f}$ transition, $\tilde{v}_{m}$ is the barycenter of the transition. It is worth noting that the very low molar absorptivity $\left(<6 \mathrm{M}^{-1} \mathrm{~cm}^{-1}\right)$ is characteristic of free $\mathrm{Ln}^{\prime \prime \prime}$ ions. The obtained value of the radiative lifetime of $\mathbf{Y b - 1}$ is given in Table 2.

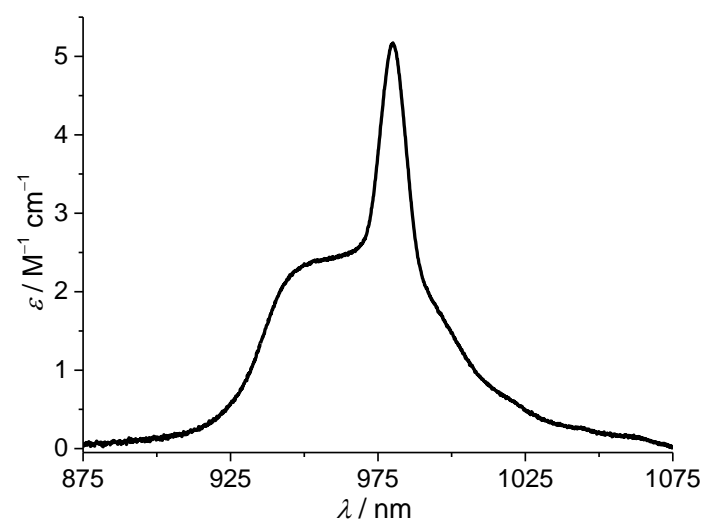

Figure 7 Absorption spectrum of the $\mathrm{Yb}-1 \mathrm{MC}$ in the range of ${ }^{2} \mathrm{~F}_{5 / 2} \leftarrow^{2} \mathrm{~F}_{7 / 2}$ transition in $\mathrm{CH}_{3} \mathrm{OH}(1.8 \mathrm{mM})$ at room temperature.

Having $\tau_{\text {rad }}$ values in hand together with the values of observed lifetimes and $Q_{\mathrm{Yb}}^{\mathrm{L}}$, intrinsic quantum yields $\left(Q_{\mathrm{Yb}}^{\mathrm{Yb}}\right)$ and sensitization efficiencies $\left(\eta_{\text {sens }}\right)$ can be calculated using the following equations $(2 a, 2 b)$ :

$Q_{\mathrm{Yb}}^{\mathrm{Yb}}=\frac{\tau_{\mathrm{obs}}}{\tau_{\mathrm{rad}}} \times 100 \%$

$\eta_{\text {sens }}=\frac{Q_{\mathrm{Yb}}^{\mathrm{L}}}{Q_{\mathrm{Yb}}^{\mathrm{Yb}}} \times 100 \%$

The results are summarized in Table 2 and compared with the values reported previously for $\mathrm{YbGa}_{4}(\mathrm{shi})_{4}(\mathrm{OBz})_{4}{ }^{26}$ and $\mathrm{YbZn}_{16}$ (quinHA) $16^{25} \mathrm{MCs}$.

\section{Discussion}

\section{Syntheses}

This work focuses on expanding the available luminescent structure types for Gall'shi metallacrowns and seeks to rationalize the photophysics associated with different Ln $^{\prime \prime \prime}$ environments in this family of molecules. The direct synthesis of MCs is often not straightforward. Therefore, in this work, the reactions between $\mathrm{H}_{3}$ shi and Gall' and a series of $\mathrm{Ln}^{\text {"II }}$ salts were screened under a variety of experimental conditions: solvent, stoichiometry, presence or absence of simple carboxylic acids, etc. Reactions of $\mathrm{Ga}\left(\mathrm{NO}_{3}\right)_{3} \cdot \mathrm{xH}_{2} \mathrm{O}, \mathrm{Ln}\left(\mathrm{NO}_{3}\right)_{3} \cdot \mathrm{yH}_{2} \mathrm{O}$ and $\mathrm{H}_{3}$ shi in a 4:1:4 molar ratio in $\mathrm{CH}_{3} \mathrm{OH} /$ pyridine led to the isolation of $\mathbf{L n - 1}$ MCs. The 4:1:4 ratio implies that the Gall' and $L^{\text {III }}$ salts are in slight excess but the increase of the amount of $\mathrm{H}_{3}$ shi did not improve the yield further. The addition of a small amount of acetic acid was found to be crucial to obtain high quality single crystals of Ln-1 MCs. The reactions also showed differences in behavior between the early and late Ln'II ions. With the same synthetic conditions described in the experimental section, the

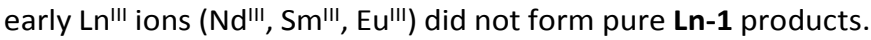
The ions located in the middle of the series (Gd"', $\mathrm{Tb}^{\prime \prime \prime}, \mathrm{Dy}^{\prime \prime \prime}, \mathrm{Ho} \mathrm{O}^{\prime \prime \prime}$ ) form complexes in which the $\mathrm{Ln}^{\prime \prime \prime}$ is nine-coordinated. For the complexes formed with the smallest Ln'I' of the series (Er'II, Tm I'I, $\left.\mathrm{Yb}^{\prime \prime \prime}\right)$, the $L \mathrm{n}^{\prime \prime \prime}$ are eight-coordinated.

Table 1 Photophysical data for Ln-1 complexes at room temperature. ${ }^{a}$

\begin{tabular}{cccc}
\hline Complex & $\Delta E\left(\mathrm{~cm}^{-1}\right)^{b}$ & $\tau_{\text {obs }}(\mu \mathrm{s})^{c}$ & $Q_{\mathrm{Ln}}^{\mathrm{L}}(\%)^{d}$ \\
\hline Tb-1 & 1260 & $509(7)$ & $11.3(5)$ \\
Dy-1 & 560 & $3.36(6)$ & $0.222(6)^{e}$ \\
Ho-1 & 6160 & $0.032(1)$ & $1.6(1) \cdot 10^{-3}$ \\
Er-1 & 14960 & $0.220(3)$ & $1.55(3) \cdot 10^{-3}$ \\
Yb-1 & 11360 & $2.99(2)$ & $0.216(6)$ \\
\hline
\end{tabular}

a $2 \sigma$ values are given between parentheses. Relative errors: $\tau_{\mathrm{obs}} \pm 2 \% ; Q_{\mathrm{Ln}}^{\mathrm{L}} \pm 10 \%$. ${ }^{b}$ $\triangle E\left({ }^{3} T-E^{\mathrm{Ln}}\right)$ is the energy gap between the ligand triplet state $\left({ }^{3} \mathrm{~T}=21660 \mathrm{~cm}^{-1}\right)$ and Ln'II emissive states: $E^{\mathrm{Tb}}\left({ }^{5} \mathrm{D}_{4}\right)=20400 \mathrm{~cm}^{-1}, E^{\mathrm{Dy}}\left({ }^{4} \mathrm{~F}_{9 / 2}\right)=21100 \mathrm{~cm}^{-1}, E^{\mathrm{Ho}}\left({ }^{5} \mathrm{~F}_{5}\right)=15500$ $\mathrm{cm}^{-1}, E^{\mathrm{Er}}\left(\left.{ }^{4}\right|_{13 / 2}\right)=6700 \mathrm{~cm}^{-1}, E^{\mathrm{Yb}}\left({ }^{2} \mathrm{~F}_{5 / 2}\right)=10300 \mathrm{~cm}^{-1} .61-63 c \lambda_{\mathrm{ex}}=355 \mathrm{~nm} \cdot{ }^{d} \lambda_{\mathrm{ex}}=350$ $\mathrm{nm} .{ }^{e}$ Total quantum yield including ligand-centered emission is equal to $0.231(8)$ $\%$. 
Table 2 Photophysical properties of the $\mathrm{Yb}-\mathbf{1} \mathrm{MC}$ in solution and comparison with other $\mathrm{Yb}^{\text {III }} \mathrm{MCs}{ }^{\circ}$

\begin{tabular}{ccccccc}
\hline Complex & Solvent & $\begin{array}{c}\tau_{\text {obs }} \\
(\mu \mathrm{s})\end{array}$ & $\begin{array}{c}\tau_{\text {rad }} \\
(\mathrm{ms})^{b}\end{array}$ & $\begin{array}{c}Q_{\mathrm{Yb}}^{\mathrm{Yb}} \\
(\%)\end{array}$ & $\begin{array}{c}Q_{\mathrm{Yb}}^{\mathrm{L}} \\
(\%)\end{array}$ & $\begin{array}{c}\eta_{\text {sens }} \\
(\%)\end{array}$ \\
\hline $\mathbf{Y b - 1}$ & $\mathrm{CD}_{3} \mathrm{OD}$ & $27.4(1)$ & 0.59 & 4.6 & $2.55(5)$ & 55 \\
& $\mathrm{CH}_{3} \mathrm{OH}$ & $1.72(1)$ & 0.59 & 0.29 & $0.123(2)$ & 42 \\
$\mathbf{Y b G a}_{4}{ }^{c}$ & $\mathrm{CD}_{3} \mathrm{OD}$ & $36.6(1)$ & 0.53 & 6.9 & $4.29(1)$ & 62 \\
& $\mathrm{CH}_{3} \mathrm{OH}$ & $2.06(4)$ & 0.53 & 0.39 & $0.26(1)$ & 67 \\
$\mathbf{Y b Z n}_{16}{ }^{d}$ & $\mathrm{CD}_{3} \mathrm{OD}$ & $150.7(2)$ & 0.68 & 22.2 & $2.88(2)$ & 13 \\
& $\mathrm{CH}_{3} \mathrm{OH}$ & $14.88(1)$ & 0.68 & 2.2 & $0.25(1)$ & 11 \\
\hline
\end{tabular}

a Relative errors: $\tau_{\mathrm{obs}} \pm 2 \% ; Q_{\mathrm{Yb}}^{\mathrm{L}}, \pm 10 \% ; \tau_{\mathrm{rad}}, \pm 10 \% ; Q_{\mathrm{Yb}}^{\mathrm{Yb}}, \pm 12 \% ; \eta_{\text {sens, }} \pm 22 \%$. ${ }^{b}$ Calculated using eq. 1 according to ref. ${ }^{60}$. For $\mathrm{CD}_{3} \mathrm{OD}$ solutions, $\tau_{\text {rad }}$ was recalculated taking into account the difference in refractive indexes, $n\left(C D_{3} O D\right)=$ 1.326. ${ }^{c} \mathrm{YbGa}_{4}(\mathrm{shi})_{4}(\mathrm{OBz})_{4}$, From ref. ${ }^{26} \cdot{ }^{d} \mathrm{YbZn}_{16}$ (quinHA) ${ }_{16}$, From ref. ${ }^{25}$.

\section{Luminescent properties}

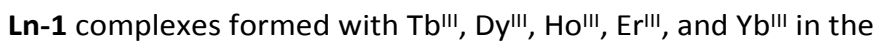
solid state exhibit characteristic emissions arising from $f-f$ transitions in the visible and/or the NIR ranges upon excitation into ligand-centered levels at $350 \mathrm{~nm}$ (Figure 5). In the emission spectrum of the Dy-1 MC, in addition to the Dy"II-centered sharp transitions, the residual broad-band ligands emission is observed reflecting an incomplete ${ }^{3} \mathrm{~T} \rightarrow{ }^{4} \mathrm{~F}_{9 / 2}$ chromophore to Dy"ll energy transfer and/or the existence of a back ${ }^{4} \mathrm{~F}_{9 / 2} \leftarrow{ }^{3} \mathrm{~T}$ energy transfer. Indeed, if long-lived triplet states are considered to be the main feeding levels for $\mathrm{Ln}^{\prime \prime \prime}$ ions, the back energy transfer may occur when the ${ }^{3} \mathrm{~T}$ state is too close to the energy of the emitting level of the $L n^{\prime \prime \prime}$ ion $\left(E^{\mathrm{Ln}}\right)$. It is assumed that, when the energy difference $\Delta E\left({ }^{3} \mathrm{~T}-E^{\mathrm{Ln}}\right)$ is $<2000 \mathrm{~cm}^{-1,21}$, there is a high possibility of back energy transfer processes. In the case of Dy-1, this energy difference $\Delta E\left({ }^{3} \mathrm{~T}-{ }^{4} \mathrm{~F}_{9 / 2}\right)$ is only 560 $\mathrm{cm}^{-1}$, therefore back energy transfer is highly probable for this $M C$. The same is true for Tb-1 with $\Delta E\left({ }^{3} T-{ }^{4} D_{4}\right)$ equal to $1260 \mathrm{~cm}$ 1. For $\mathrm{Ln}-1 \mathrm{MCs}$ formed with all other $\mathrm{Ln}^{\prime \prime \prime}, \Delta E$ is $>6000 \mathrm{~cm}^{-1}$, thus preventing a back energy transfer to the ${ }^{3} T$ level. It should be noted that the position of the triplet state in $\mathbf{L n - 1}\left(21660 \mathrm{~cm}^{-1}\right)$ is very close in energy to those reported previously for the monomeric $\mathrm{LnGa}_{4}(\mathrm{shi})_{4}(\mathrm{OBz})_{4}\left({ }^{3} \mathrm{~T}=22170 \mathrm{~cm}^{-1}\right)^{26}$ and for the dimeric $\mathrm{Ln}_{2} \mathrm{Ga}_{8}(\mathrm{shi})_{8}(\mathrm{iph})_{4}\left({ }^{3} \mathrm{~T}=21980 \mathrm{~cm}^{-1}\right)^{28} \mathrm{MCs}$ assembled using salicylhydroxamic acid. Nevertheless, Ln'II-centered quantum yield values collected under ligands excitation $\left(Q_{\mathrm{Ln}}^{\mathrm{L}}\right)$ and observed lifetimes ( $\tau_{\mathrm{obs}}$ ) (Table 1 ) of Ln-1 MCs are lower than these recorded for $\operatorname{LnGa}_{4}(\mathrm{shi})_{4}(\mathrm{OBz})_{4}{ }^{26}$ or $\mathrm{Ln}_{2} \mathrm{Ga}_{8}(\mathrm{shi})_{8}(\mathrm{iph})_{4}{ }^{28}$ In the case of Tb-1 and Dy-1, such behavior could be explained by the enhanced back energy transfer processes, while for Ln-1 MCs formed with other Ln"I', the reason most probably lies in the structural feature of $\mathbf{L n - 1}$ as

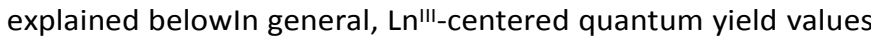
collected under ligands excitation $\left(Q_{\mathrm{Ln}}^{\mathrm{L}}\right)$ and observed luminescence lifetimes ( $\tau_{\mathrm{obs}}$ ) (Table 1 ) of $\mathbf{L n - 1}$ MCs are following the energy gap law, i.e. the smaller the energy gap between the lowest level of the emitting and the highest level of the ground states, the higher is the probability of the quenching of $\mathrm{Ln}^{\text {"II }}$ through overtones of high energy vibrations, like $\mathrm{O}-\mathrm{H}, \mathrm{N}-\mathrm{H}, \mathrm{C}-$ $\mathrm{H} .{ }^{64}$ The highest $Q_{\mathrm{Ln}}^{\mathrm{L}}$ and the longest $\tau_{\mathrm{obs}}$ values are observed for Tb-1 MC, while lower values were measured for Dy-1, Yb-1 and Er-1. Ho ${ }^{\prime \prime \prime}$ ions coordinated in complexes with organic ligands usually exhibit very weak luminescence intensities.65-68 Nevertheless, for the Ho-1 MC, quantitative parameters could be accurately acquired (Table 1 ).

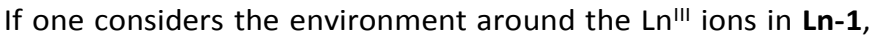
the presence of two incompletely deprotonated $\mathrm{H}_{2}$ shi- ligands implies $\mathrm{N}-\mathrm{H}$ and $\mathrm{O}-\mathrm{H}$ groups being in close proximity to the $\mathrm{Ln}^{\prime \prime \prime}$. These high-energy oscillators are the main sources of nonradiative deactivations, in particular for L ${ }^{\prime \prime \prime}$ with small energy gaps between the emitting and the ground levels. ${ }^{21,}{ }^{23}$ Such feature of Ln-1 MCs could explain their lower $Q_{\mathrm{Ln}}^{\mathrm{L}}$ and shorter $\tau_{\text {obs }}$ values compared to the previously reported $\mathrm{Ln}^{\text {"II/Ga"II }}$ MCs. ${ }^{26,} 28$ Moreover, the presence of water and methanol solvent molecules in the lattice of $\mathbf{L n}-\mathbf{1}$ and intermolecular interactions due to $\pi-\pi$ stacking ( $d=3.55 \AA$ for Yb-1, Figure S3) could serve as additional sources of non-radiative deactivations of $\mathrm{Ln}^{\mathrm{III}}$ ions and induces the lowering of their luminescence.

To quantitatively assess the parameters that affect $Q_{\mathrm{Ln}}^{\mathrm{L}}$, sensitization efficiencies and intrinsic quantum yields have to be estimated. $Q_{\mathrm{Ln}}^{\mathrm{Ln}}$ can be obtained by the direct excitation of $\mathrm{Ln}^{\prime \prime \prime}$ into $f-f$ transitions; however, such measurements are often tricky due to the low molar absorptivities of $f-f$ transitions. Another method to obtain $Q_{\mathrm{Ln}}^{\mathrm{Ln}}$ involves the determination of $\tau_{\text {obs }}$ and $\tau_{\text {rad }}$ according to eq. 2 a. Observed luminescence lifetime can be routinely measured whereas the determination of $\tau_{\text {rad }}$ is not as straightforward. It is worth noting here that $\tau_{\text {rad }}$ is specific for the Ln'I' coordination environment and the electronic transition involved in the emission. ${ }^{69}$ This parameter is getting an increased attention recently as controlling $\tau_{\text {rad }}$ has been shown to be a promising strategy to significantly improve efficiencies of visible- and NIR-emitting $\mathrm{Ln}^{\mathrm{III}}$ complexes. ${ }^{70-72}$ Radiative lifetime can be estimated from the modified Einstein's equation (eq. 1) if the absorption spectrum that corresponds to the emission one is known. Among all studied Ln-1, such procedure could be applied only for Yb-1 in methanol solution. The value of $\tau_{\text {rad }}$ equal to $0.59 \mathrm{~ms}$ was found (Table 2). This parameter is very close to the $\tau_{\text {rad }}$ value reported for $\mathrm{YbGa}_{4}(\mathrm{shi})_{4}(\mathrm{OBz})_{4}(0.53 \mathrm{~ms})^{26}$ and slightly shorter than the one for $\mathrm{YbZn}_{16}$ (quinHA) ${ }_{16}{ }^{25}$ Taking into account $\tau_{\mathrm{obs}}$ and $Q_{\mathrm{Yb}}^{\mathrm{L}}$ values in the corresponding solvents, $Q_{\mathrm{Yb}}^{\mathrm{Yb}}$ were estimated to be $4.6 \%$ in $\mathrm{CD}_{3} \mathrm{OD}$ and $0.29 \%$ in $\mathrm{CH}_{3} \mathrm{OH}$ with sensitization efficiencies of $55 \%$ and $42 \%$, respectively. In comparison to the previously reported $\mathrm{Yb}^{\text {"II }} \mathrm{MCs},{ }^{25},{ }^{26} \mathbf{Y b}-\mathbf{1}$ exhibits $\eta_{\text {sens }}$ four times higher than the one for $\mathrm{YbZn}_{16}$ (quinHA) ${ }_{16}$ and only slightly lower than the one of $\mathrm{YbGa}_{4}(\mathrm{shi})_{4}(\mathrm{OBz})_{4}$. However, the $Q_{\mathrm{Yb}}^{\mathrm{Yb}}$ value for $\mathrm{Yb}-1$ is 57 times lower than in the case of $\mathrm{YbZn}_{16}$ (quinHA) ${ }_{16}$ and 1.5 times lower than for $\mathrm{YbGa}_{4}(\mathrm{shi})_{4}(\mathrm{OBz})_{4}$. As a result, $\mathrm{Yb}-\mathbf{1}$ has a $Q_{\mathrm{Yb}}^{\mathrm{L}}$ value in $\mathrm{CD}_{3} \mathrm{OD}$ which is only slightly lower than the one for $\mathrm{YbZn}_{16}$ (quinHA) $)_{16}$ but 1.7 times smaller than the one for $\mathrm{YbGa}_{4}(\mathrm{shi})_{4}(\mathrm{OBz})_{4}$. In respect to luminescence efficiency, defined as $Q_{\mathrm{Yb}}^{\mathrm{L}} \times \varepsilon$, the lower $Q_{\mathrm{Yb}}^{\mathrm{L}}$ of $\mathrm{Yb}-\mathbf{1}$ in solution compared to $\mathrm{YbGa}_{4}(\mathrm{shi})_{4}(\mathrm{OBz})_{4}$ can be almost fully compensated by the 1.5 times higher molar absorptivity of the former due to the contribution of six ligands instead of four shi- ligands for the latter.

\section{Conclusions}


Via direct synthesis, we have obtained and fully characterized a new series of visible and NIR-emitting LnGa 4 MCs. Factors that affect luminescence intensities such as the energy levels of triplet states, molar absorptivities, non-radiative deactivation through vibronic coupling with overtones of $\mathrm{O}-\mathrm{H}, \mathrm{N}-\mathrm{H}$, and $\mathrm{C}-\mathrm{H}$ oscillators, and crystal packing were discussed in details. In conclusion, designing MCs is a fully innovative and versatile approach to create lanthanide(III) complexes with high luminescence intensities. With a broad variety of available chromophoric structures, ligands that can be used to form MCs, there is an unprecedented number of possibilities to construct several families of lanthanide(III)-based luminescent MCs with controlled properties that can be used for a broad range of applications such as bioanalyis and bioimaging.

\section{Conflicts of interest}

There are no conflicts to declare.

\section{Acknowledgements}

The research leading to these results have received funding from the European Community's Seventh Framework Program (IRSES Metallacrown - FP7/2007-2013) under grant agreement $\mathrm{n}^{\circ} 611488$. This research was also supported in part by the National Science Foundation under grant CHE-1361779, La Ligue contre le Cancer and La Région Centre. S.P. acknowledges support from Institut National de la Santé et de la Recherche Médicale (INSERM).

\section{References}

1. M. Chalfie, Y. Tu, G. Euskirchen, W. Ward and D. Prasher, Science, 1994, 263, 802-805.

2. X.-F. Zhang, J. Zhang and L. Liu, J. Fluoresc., 2014, 24, 819-826.

3. J. Yang, Y. Zhang, S. Gautam, L. Liu, J. Dey, W. Chen, R. P. Mason, C. A. Serrano, K. A. Schug and L. Tang, Proc. Nat. Acad. Sci., 2009, 106, 10086-10091.

4. L. Martínez Maestro, C. Jacinto, U. Rocha, M. Carmen Iglesias-de la Cruz, F. Sanz-Rodriguez, A. Juarranz, J. García Solé and D. Jaque, J. Appl. Phys., 2012, 111, 023513.

5. S. Banerjee, C. D. Malliakas, J. I. Jang, J. B. Ketterson and M. G. Kanatzidis, J. Am. Chem. Soc., 2008, 130, 12270-12272.

6. V. W.-W. Yam and K. M.-C. Wong, Chem. Commun., 2011, 47, 11579-11592.

7. L. Armelao, S. Quici, F. Barigelletti, G. Accorsi, G. Bottaro, M. Cavazzini and E. Tondello, Coord. Chem. Rev., 2010, 254, 487-505.

8. T. N. Nguyen, F. M. Ebrahim and K. C. Stylianou, Coord. Chem. Rev., 2018, 377, 259-306.

9. L. D. Carlos, R. A. S. Ferreira, V. de Zea Bermudez, B. Julian-Lopez and P. Escribano, Chem. Soc. Rev., 2011, 40, 536-549.

10. J.-C. G. Bünzli, J. Lumin., 2016, 170, 866-878.

11. J.-C. G. Bünzli and A.-S. Chauvin, in Handbook on the Physics and Chemistry of Rare Earths, eds. J.-C. G. Bünzli and V. K. Pecharsky, Elsevier Science, B.V., Amsterdam, 2013, vol. 44, Ch. 261, pp. 169282.
12. H. Dong, S. R. Du, X. Y. Zheng, G. M. Lyu, L. D. Sun, L. D. Li, P. Z. Zhang, C. Zhang and C. H. Yan, Chem. Rev., 2015, 115, 10725-10815. 13. K. Binnemans, Chem. Rev., 2009, 109, 4283-4374.

14. J. Feng and H. J. Zhang, Chem. Soc. Rev., 2013, 42, 387-410.

15. M. Sy, A. Nonat, N. Hildebrandt and L. J. Charbonniere, Chem. Commun., 2016, 52, 5080-5095.

16. I. Martinić, S. V. Eliseeva and S. Petoud, J. Lumin., 2017, 189, 1943.

17. G. X. Bai, M. K. Tsang and J. H. Hao, Adv. Funct. Mater., 2016, 26, 6330-6350.

18. J.-C. G. Bunzli, Chem. Rev., 2010, 110, 2729-2755.

19. T. N. Nguyen, G. Capano, A. Gładysiak, F. M. Ebrahim, S. V. Eliseeva, A. Chidambaram, B. Valizadeh, S. Petoud, B. Smit and K. C. Stylianou, Chem. Commun., 2018, 54, 6816-6819.

20. F. M. Ebrahim, T. N. Nguyen, S. Shyshkanov, A. Gładysiak, P. Favre, A. Zacharia, G. Itskos, P. J. Dyson and K. C. Stylianou, J. Am. Chem. Soc., 2019, 141, 3052-3058.

21. J.-C. G. Bünzli and S. V. Eliseeva, in Comprehensive Inorganic Chemistry II, ed. V. W.-W. Yam, Elsevier B.V., Amsterdam, 2013, vol. 8, ch. 8.08, pp. 339-398.

22. H. Uh and S. Petoud, C. R. Chim, 2010, 13, 668-680.

23. J.-C. G. Bünzli, Coord. Chem. Rev., 2015, 293-294, 19-47.

24. J. Jankolovits, C. M. Andolina, J. W. Kampf, K. N. Raymond and V. L. Pecoraro, Angew. Chem. Int. Ed., 2011, 50, 9660-9664.

25. E. R. Trivedi, S. V. Eliseeva, J. Jankolovits, M. M. Olmstead, S. Petoud and V. L. Pecoraro, J. Am. Chem. Soc., 2014, 136, 1526-1534. 26. C. Y. Chow, S. V. Eliseeva, E. R. Trivedi, T. N. Nguyen, J. W. Kampf, S. Petoud and V. L. Pecoraro, J. Am. Chem. Soc., 2016, 138, 51005109.

27. J. C. Lutter, S. V. Eliseeva, J. W. Kampf, S. Petoud and V. L. Pecoraro, Chem. Eur. J., 2018, 24, 10773-10783.

28. T. N. Nguyen, C. Y. Chow, S. V. Eliseeva, E. R. Trivedi, J. W. Kampf, I. Martinić, S. Petoud and V. L. Pecoraro, Chem. Eur. J., 2018, 5, 10311035.

29. I. Martinić, S. V. Eliseeva, T. N. Nguyen, F. Foucher, D. Gosset, F. Westall, V. L. Pecoraro and S. Petoud, Chem. Sci., 2017, 8, 6042-6050. 30. I. Martinić, S. V. Eliseeva, T. N. Nguyen, V. L. Pecoraro and S. Petoud, J. Am. Chem. Soc., 2017, 139, 8388-8391.

31. G. Mezei, C. M. Zaleski and V. L. Pecoraro, Chem. Rev., 2007, 107, 4933-5003.

32. A. D. Cutland, R. G. Malkani, J. W. Kampf and V. L. Pecoraro, Angew. Chem. Int. Ed., 2000, 39, 2689-2691.

33. C.-S. Lim, J. Jankolovits, P. Zhao, J. W. Kampf and V. L. Pecoraro, Inorg. Chem., 2011, 50, 4832-4841.

34. J. T. Grant, J. Jankolovits and V. L. Pecoraro, Inorg. Chem., 2012, 51, 8034-8041.

35. C. Sgarlata, A. Giuffrida, E. R. Trivedi, V. L. Pecoraro and G. Arena, Inorg. Chem., 2017, 56, 4771-4774.

36. J. Jankolovits, C. S. Lim, G. Mezei, J. W. Kampf and V. L. Pecoraro, Inorg. Chem., 2012, 51, 4527-4538.

37. J. Jankolovits, A. D. C. Van-Noord, J. W. Kampf and V. L. Pecoraro, Dalton Trans., 2013, 42, 9803-9808.

38. H. Piotrowski, K. Polborn, G. Hilt and K. Severin, J. Am. Chem. Soc., 2001, 123, 2699-2700.

39. C. Y. Chow, H. Bolvin, V. E. Campbell, R. Guillot, J. W. Kampf, W. Wernsdorfer, F. Gendron, J. Autschbach, V. L. Pecoraro and T. Mallah, Chem. Sci., 2015, 6, 4148-4159.

40. T. T. Boron, J. C. Lutter, C. I. Daly, C. Y. Chow, A. H. Davis, A. Nimthong-Roldán, M. Zeller, J. W. Kampf, C. M. Zaleski and V. L. Pecoraro, Inorg. Chem., 2016, 55, 10597-10607. 
41. C. M. Zaleski, S. Tricard, E. C. Depperman, W. Wernsdorfer, T. Mallah, M. L. Kirk and V. L. Pecoraro, Inorg. Chem., 2011, 50, 1134811352.

42. C. M. Zaleski, E. C. Depperman, J. W. Kampf, M. L. Kirk and V. L. Pecoraro, Inorg. Chem., 2006, 45, 10022-10024.

43. C. M. Zaleski, E. C. Depperman, C. Dendrinou-Samara, M. Alexiou, J. W. Kampf, D. P. Kessissoglou, M. L. Kirk and V. L. Pecoraro, J. Am. Chem. Soc., 2005, 127, 12862-12872.

44. C. M. Zaleski, E. C. Depperman, J. W. Kampf, M. L. Kirk and V. L. Pecoraro, Angew. Chem. Int. Ed., 2004, 43, 3912-3914.

45. T. T. Boron, J. W. Kampf and V. L. Pecoraro, Inorg. Chem., 2010, 49, 9104-9106.

46. P. Happ and E. Rentschler, Dalton Trans., 2014, 43, 15308-15312. 47. P. Happ, C. Plenk and E. Rentschler, Coord. Chem. Rev., 2015, 289-290, 238-260.

48. C. Y. Chow, R. Guillot, E. Rivière, J. W. Kampf, T. Mallah and V. L. Pecoraro, Inorg. Chem., 2016, 55, 10238-10247.

49. M. S. Muravyeva, G. S. Zabrodina, M. A. Samsonov, E. A. Kluev, A. A. Khrapichev, M. A. Katkova and I. V. Mukhina, Polyhedron, 2016, 114, 165-171.

50. M. A. Katkova, G. S. Zabrodina, M. S. Muravyeva, A. S. Shavyrin, E. V. Baranov, A. A. Khrapichev and S. Y. Ketkov, Eur. J. Inorg. Chem. 2015, 5202-5208.

51. T. N. Parac-Vogt, A. Pacco, P. Nockemann, S. Laurent, R. N. Muller, M. Wickleder, G. Meyer, L. Vander Elst and K. Binnemans, Chem. Eur. J., 2006, 12, 204-210.

52. J. Jankolovits, C. M. Andolina, J. W. Kampf, K. N. Raymond and V. L. Pecoraro, Angew. Chem. Int. Ed., 2011, 50, 9660-9664.

53. G. M. Sheldrick, Acta. Cryst. A, 2008, 64, 112-122.

54. A. L. Spek, Platon, A Multipurpose Crystallographic Tool, Utrecht University; Utrecht, The Netherlands, 2001.

55. A. Ruiz-Martinez, D. Casanova and S. Alvarez, Dalton Trans., 2008, DOI: 10.1039/B718821H, 2583-2591.

56. S. Tobita, M. Arakawa and I. Tanaka, J. Phys. Chem., 1985, 89, 5649-5654.

57. W. T. Carnall, P. R. Fields and K. Rajnak, J. Chem. Phys., 1968, 49, 4443-4446.

58. M. Ganapathi, S. V. Eliseeva, N. R. Brooks, D. Soccol, J. Fransaer and K. Binnemans, J. Mater. Chem., 2012, 22, 5514-5522.

59. A. Beeby, I. M. Clarkson, R. S. Dickins, S. Faulkner, D. Parker, L. Royle, A. S. de Sousa, J. A. G. Williams and M. Woods, J. Chem. Soc., Perkin Trans. 2, 1999, 493-503.

60. M. H. V. Werts, R. T. F. Jukes and J. W. Verhoeven, Phys. Chem Chem. Phys., 2002, 4, 1542-1548.

61. W. T. Carnall, P. R. Fields and K. Rajnak, J. Chem. Phys., 1968, 49, 4450-4455.

62. W. T. Carnall, P. R. Fields and K. Rajnak, J. Chem. Phys., 1968, 49, 4447-4449.

63. W. T. Carnall, P. R. Fields and K. Rajnak, J. Chem. Phys., 1968, 49, 4424-4442.

64. J.-C. Bünzli and S. Eliseeva, in Lanthanide Luminescence, eds. P. Hänninen and H. Härmä, Springer Berlin Heidelberg, 2011, vol. 7, ch. 3, pp. 1-45.

65. G. L. Law, T. A. Pham, J. D. Xu and K. N. Raymond, Angew. Chem. Int. Ed., 2012, 51, 2371-2374.

66. Z. Ahmed and K. Iftikhar, J. Phys. Chem. A, 2013, 117, 1118311201.

67. N. Wartenberg, O. Raccurt, E. Bourgeat-Lami, D. Imbert and M. Mazzanti, Chem. Eur. J., 2013, 19, 3477-3482.

68. A. F. Martins, S. V. Eliseeva, H. F. Carvalho, J. M. Teixeira, C. T. Paula, P. Hermann, C. Platas-Iglesias, S. Petoud, E. Toth and C. F. Geraldes, Chem. Eur. J., 2014, 20, 14834-14845.
69. J.-C. G. Bünzli, A.-S. Chauvin, H. K. Kim, E. Deiters and S. V. Eliseeva, Coord. Chem. Rev., 2010, 254, 2623-2633.

70. C. Doffek and M. Seitz, Angew. Chem. Int. Ed., 2015, 54, 97199721.

71. N. M. Shavaleev, S. V. Eliseeva, R. Scopelliti and J.-C. G. Bunzli, Inorg. Chem., 2015, 54, 9166-9173.

72. N. M. Shavaleev, R. Scopelliti, F. Gumy and J.-C. G. Bünzli, Inorg. Chem., 2009, 48, 7937-7946. 